\title{
First Presentation of the Complete Infection Cycle of Visceralizing Leishmania infantum/ donovani Hybrid Strain in Turkey: The Host, Reservoir and Vector
}

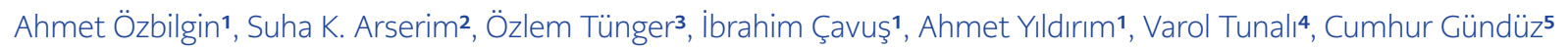

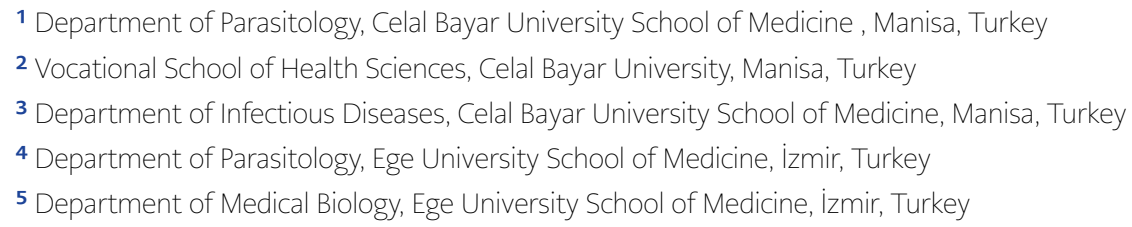

\section{ABSTRACT}

Objective: Visceral Leishmaniasis (VL) is a widespread infectious disease of the reticuloendothelial system which is mostly caused by Leishmania infantum and L.donovani. VL is a zoonotic infection and dogs act as the main reservoirs of the disease while the vectors are the female Phlebotomus, that is to say, sandflies. Although Leishmania spp. are attributed to reproduce asexually, the genetic exchange between different strains has recently been demonstrated and causes interspecific hybrids. We aimed to present the complete infection cycle of a hybrid strain of Leishmania infantum/donovani with the host, reservoir, and vector.

Materials and Methods: A patient presenting with VL proved to have a dog with canine leishmaniasis. Bone marrow aspirate from the patient and lymph node aspirates from the dog were inspected for Leishmania spp. amastigotes under light microscopy. Samples were cultured in enriched NNN medium. Serological examinations were made using IFAT for the patient serum and rK39 test for both human and dog samples. Light traps were placed to collect Phlebotomus. Leishmania molecular identification was executed by primers and probes specific to ITS-1 and cytochrome B gene region of Leishmania parasites.

Results: Leishmania spp. amastigotes were detected in the slides while promastigotes were present in the enriched NNN medium. For patient serum, IFAT IgG was 1/256 positive, and rK39 was positive for both dog and human samples. Fifty-two Phlebotomus were caught (24 male, 28 female): 35 of them were P. similis, ten were P. neglectus/syriacus, six were P .papatasi, and one was P. tobbi. Molecular analysis showed that the Leishmania spp. isolates from the patient, dog, and P.tobbi were identical. Gel image revealed two bands in all three samples, thus leading to the conclusion that the infecting strain was a hybrid of L. infantum and $L$. donovani.

Conclusion: We found identical isolates that are putative hybrids of $L$. donovani and $L$. infantum in human, dog reservoir and sandfly.

Keywords: Leishmaniasis, Phlebotomus, Hybrid, Epidemiology, Migration, Turkey
Corresponding Author: Varol Tunalı

E-mail:

varoltunali@gmail.com

Received: December 30, 2019

Accepted: April 8, 2020

Published: April 30, 2020

\section{Suggested citation:}

Özbilgin A, Arserim S.K, Tünger Ö, Çavuş I, Yıldırım A, Tunalı V, et al. First Presentation of the Complete Infection Cycle of Visceralizing Leishmania infantum/ donovani Hybrid Strain in Turkey: The Host, Reservoir and Vector Infect Dis Clin Microbiol 2020; 1: 8-15.

DOI: $10.36519 / \mathrm{idcm} .2019 .0032$ 


\section{INTRODUCTION}

V isceral Leishmaniasis (VL) is a widespread infectious disease of the reticuloendothelial system which is mostly caused by Leishmania infantum (L. infantum) and L. donovani in the Old World. The disease is endemic in many parts of the world, and estimated cases of VL have reached 300,000 globally with a high rate of HIV co-infection, and over 20,000-40,000 deaths annually (1). Visceral leishmaniasis, also known as kala-azar, is a zoonotic infection; recent reports point to the zoonotic involvement of $\mathrm{L}$. donovani and dogs act as the main animal reservoirs of the disease while the vectors are the female Phlebotomus (sandflies) (2).

Turkey is situated on the crossroads between continents and acts as a bridge for people crossing to Europe from Asian and African countries like Turkmenistan, Pakistan, Afghanistan, Sudan, Nigeria and Ethiopia where VL is endemic (3).

With a total of 14,587 Cutaneous Leishmaniasis (CL) and 207 VL cases reported between the years 20052014, Leishmaniasis is an important public health issue in Turkey (4). Several species of Phlebotomus are present in Turkey. Until now 22 species of Phlebotomus and Sergentomyia have been reported from the country (5), and some of these Phlebotomus are proven vectors of leishmaniasis (e.g. Phlebotomus neglectus, $P$. papatasi, P. perfiliewi, P. sergenti, P. similis, and P. tobbi) (6).

The genetic exchange and hybridization have been demonstrated in trypanosomatid parasites. (7) Although asexual reproduction has been attributed to Leishmania spp., the genetic exchange has recently been demonstrated in laboratory studies (8) which was followed by other publications exploring mechanisms of hybridization in Leishmania spp. $(9,10)$. Both by molecular findings and analysis, it has recently been demonstrated that Leishmania spp. can form hybrids and Leishmania spp. show a high genetic variation. These findings led to the discussion that the currently identified strains are invalid, and the taxonomy should be restructured (11).

The genetic exchange seen in Leishmania spp. has considerable effects on epidemiology, biology, pathology, diagnosis, and treatment of Leishmaniasis
(12). Naturally occurring hybrid forms of Leishmania spp. were also published, but the focus of these studies was mainly the parasite and not the clinical propagation of the disease caused by the hybrid strain. $(13,14)$

In this study, we aimed to investigate the clinical propagation of the naturally occurring disease in the human and dog which are infected by the hybrid strain of L. infantum/donovani and to analyze the vector Phlebotomus spp. using molecular methods, for the first time in Turkey.

\section{MATERIALS AND METHODS}

\section{Study Population}

The patient was a 27-year-old male security officer working in Manisa. He was living in Manisa in a 200 $\mathrm{m}^{2}$ house made of stones and sand bricks with a garden that has white mulberry and blackberry trees. It was observed that the family was using some part of the garden as living grounds and that they kept a four-year-old female dog at the same place. He was sleeping in the garden next to the dog in warm summer nights, without using a mosquito net (Figure 1).

Before his visit to a general practitioner, the patient had symptoms like fever, shivers, night sweating, fatigue, myalgia and weight loss (12 kg in 6 weeks) for six weeks. He was prescribed symptomatic medication for viral upper respiratory tract infection

\section{HIGHLIGHTS}

- A hybrid strain of Leishmania infantum and Leishmania donovani has been discovered

- To our knowledge, the complete infection cycle of the hybrid strain has been unveiled with the host, reservoir and the vector for the first time in the literature

- The clinical aspects of the infection in the human host and the dog reservoir has been documented

- Effects of migration and suitable climatic and environmental conditions to the hybrid formation have been discussed thoroughly 
and was externalized. Without any relief after using the medication, the patient applied to a secondary level hospital and was prescribed antibiotics. His fever was still high even after the antibiotic regimen, so he was hospitalized in the same hospital and was given moxifloxacin and ceftriaxone empirically. The blood tests could not maintain any solid diagnosis, and the patient was transferred to Celal Bayar University Medical Faculty Hospital with the fever of unknown origin pre-diagnosis.

Laboratory tests for the infectious and non-infectious causes of fever, such as non-specific bacteriologic and mycobacteriology cultures, viral serologic tests, auto-immune markers, thyroid function tests were performed. Besides, radiologic tests, such as chest $\mathrm{x}$-ray, abdominal ultrasound, abdominal and thoracal CT, echocardiography, were performed to detect the cause of fever of unknown origin. The patient having fever, splenomegaly, and pancytopenia was assessed for malaria using thin and thick blood smears.

Consultations were made from haematology and rheumatology departments because of splenomegaly and pancytopenia. Bone marrow samples were sent to the haematology department for possible malignant causes and parasitology department for parasitological examination.

\section{Canine Leishmaniasis (CanL) Case History Analysis}

The physical examination of the CanL case revealed conjunctivitis, blepharitis, weight loss, fatigue, loss of appetite, skin ulceration, onychogryphosis, epistaxis, alopecia, lymphadenopathy (LAP) and splenomegaly. Most of the symptoms were present for the last six months.

\section{Sample Collection}

Blood and bone marrow samples were obtained from the patient using intravenous catheterization and fine-needle aspiration, respectively. Five $\mathrm{ml}$ of blood was drawn from the dog via the brachial vein and serum was separated (15) followed by lymph node aspiration for the parasitological examination.

Sandflies were collected using Centers for Disease Control and Prevention (CDC) light traps. Light

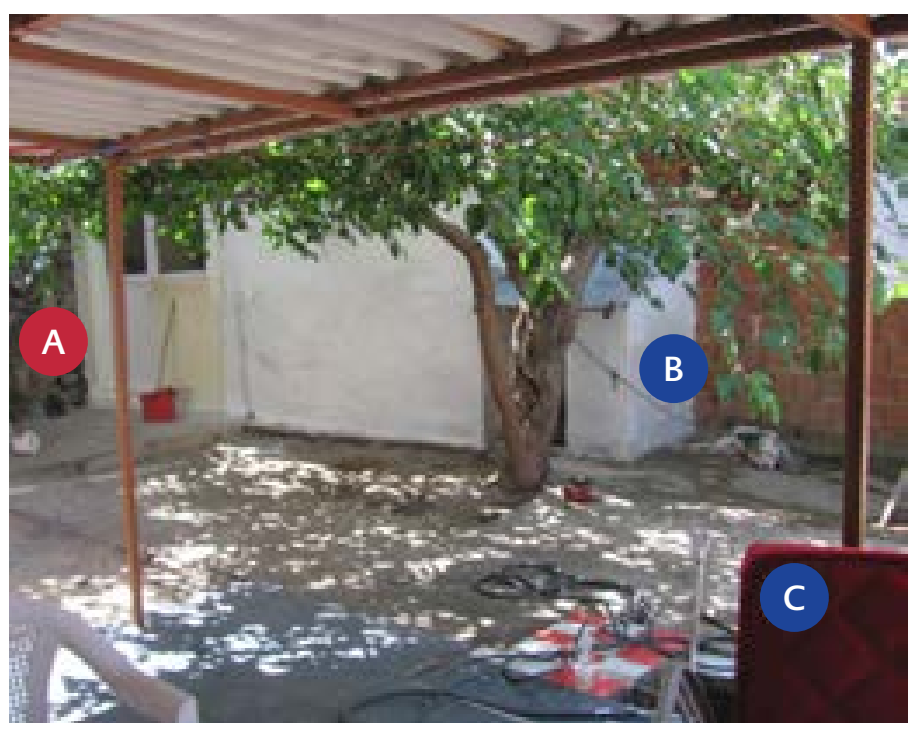

Figure 1. The photo of the garden where the infection cycle was enabled. A: The stone wall where the phlebotomus were caught B: The dog's open air residence under the mulberry tree $\mathrm{C}$ : The sofa where the host was using to sleep in warm summer nights.



Figure 2. A: CDC light traps used to collect Phlebotomus B: A specimen of the caught Phlebotomus

traps were set in the garden, the patient's and dog's living grounds as well as 100 meters radius around the house (Figure 2). The light traps were operated for three nights between 6.00 p.m. -11.00 a.m., and the sandflies were collected every morning between 09.00-11.00. Following the collection, they were morphologically identified and dissected. The female flies' tissues were crushed for DNA isolation.

\section{Direct Microscopy and Culture Methods}

Bone marrow and lymph node aspirates were inspected for Leishmania spp. amastigotes under light 
microscopy (x1000 augmentation) from Giemsa stained slides after fixation with methyl alcohol. Furthermore, the samples were cultured in biphasic enriched Novy- MacNeal- Nicolle (NNN) medium containing saline solution, defibrinated rabbit blood and enriched agar using beef infusion, liver, and yeast extracts (16). The obtained mixture was then distributed to sterile tubes, each consisting of four millilitres of the mix. After keeping the tubes in room temperature until solidification, the tubes were transferred to $+4{ }^{\circ} \mathrm{C}$ fridges. For the liquid compartment of the medium, $1 \mathrm{ml}$ of RPMI-1640 medium containing $15 \%$ fetal calf serum was used. The media were kept in ovens at $25^{\circ} \mathrm{C}$ and were inspected for the existence of promastigotes every day. Following detection, the liquid content of the media was transferred to flasks containing RPMI1640 for the rapid production of promastigotes. The promastigotes were then collected from the RPMI1640 medium and planted in a petri dish containing the solid phase of the EM to obtain a single colony for molecular purposes (17).

\section{Serological and Molecular Analysis}

The blood samples drawn from the patient were centrifuged to separate the serum. The patient sera were used for the Indirect Fluorescent Antibody Test (IFAT). An rK39 dipstick test was also performed for both the human and dog samples.

\section{Real-time ITS-I PCR}

Primers and probes used for the real-time ITS1PCR method were Old World species-specific (L. tropica, L. major, L. infantum, L. donovani). The procedure which was described previously by Töz et al. was followed (18). In short, the $25 \mu \mathrm{l}$ final mixture for the real-time PCR analysis consisted of; 12,5 $\mu$ l QuantiTect Probe PCR kit master (Qiagen), $10 \mathrm{Mm}$ of each primer (forward primer 5'-CTGGATCATTT-TCCGATG, reverse primer 5'- GAAGCCAAGTCATCCATCGC -3') 4,5 $\mu$ l PCR Grade water, $4 \mu \mathrm{M}$ of each probe and $20 \mathrm{ng}$ genomic DNA. The protocol that was used in the Real-time PCR device (Rotor-Gene ${ }^{\circledR}$ Q) is; $95^{\circ} \mathrm{C}$ forward denaturation for 15 minutes followed by 40 cycles (denaturation at $95^{\circ} \mathrm{C}$ for $15 \mathrm{sec}$ onds, binding at $50^{\circ} \mathrm{C}$ for 30 seconds and 20 seconds at $72^{\circ} \mathrm{C}$ for elongation) and termination at $95^{\circ} \mathrm{C}$ for one minute and 1 minute at $40^{\circ} \mathrm{C}$. Melting curve analysis was employed for species discrimination. Species identification was made by comparing the positive controls with the melting curve results of the specimens.

We used four Leishmania strains reference of The World Health Organisation for controls: L. major (MHOM/SU/1973/5ASKH), L. tropica (MHOM/ AZ/1974/SAF-K27, MHOM/IL/1990/LRC-L590), L. donovani (MHOM/IN/80/DD8) and L. infantum (MHOM/ TN/80/IPT1).

\section{Cysteine Protease b (CPB) Gene PCR}

A PCR of the CPB gene region that discerns differences between L. infantum and L. donovani was also performed as described previously by Hide and Bañuls (19). In brief, a real-time PCR was carried out using primers that were previously designed (unpublished data, provided as Supplementary Material) and PCR was run on Rotor-Gene ${ }^{\circledR}$ device (Qiagen, Germany) according to manufacturer's instructions. The PCR amplification products are dyed with SYBR green nucleic acid dye and visualized under UV light following gel electrophoresis with $2 \%$ agarose gel.

\section{RESULTS}

\section{Patient Findings}

The patient's physical examination revealed; traube was closed, the right costovertebral angle was tender and splenomegaly was observed. His blood investigations showed pancytopenia with a leucocyte count of 2600/mm3, haemoglobin level of $9.7 \mathrm{~g} / \mathrm{dl}$ and thrombocyte count of $62000 / \mathrm{mm} 3$. In the abdominal computed tomography (CT), the liver was noted as $18 \mathrm{~cm}$ and spleen as $18,5 \mathrm{~cm}$ with normal parenchymal echogenicity. There were several lymph nodes in para-aortic and para-iliac regions not exceeding one $\mathrm{cm}$. Not being able to find the cause of the fever with the tests, empiric piperacillin-tazobactam was administered to him for pancytopenia.

\section{Parasitological and Molecular Evaluation}

The peripheric and thick blood smears were evaluated as negative for malaria. Leishmania spp. amastigotes were detected in the slides prepared from 
Table 1. Distribution of Phlebotomus spp.

\begin{tabular}{|l|l|l|l|}
\hline Species & Male & Female & Total \\
\hline P.similis & 12 & 23 & 35 \\
\hline P. neglectus/syriacus & 9 & 1 & 10 \\
\hline P. papatasi & 3 & 3 & 6 \\
\hline P.tobbi & 0 & 1 & 1 \\
\hline Total & 24 & 28 & 52 \\
\hline
\end{tabular}

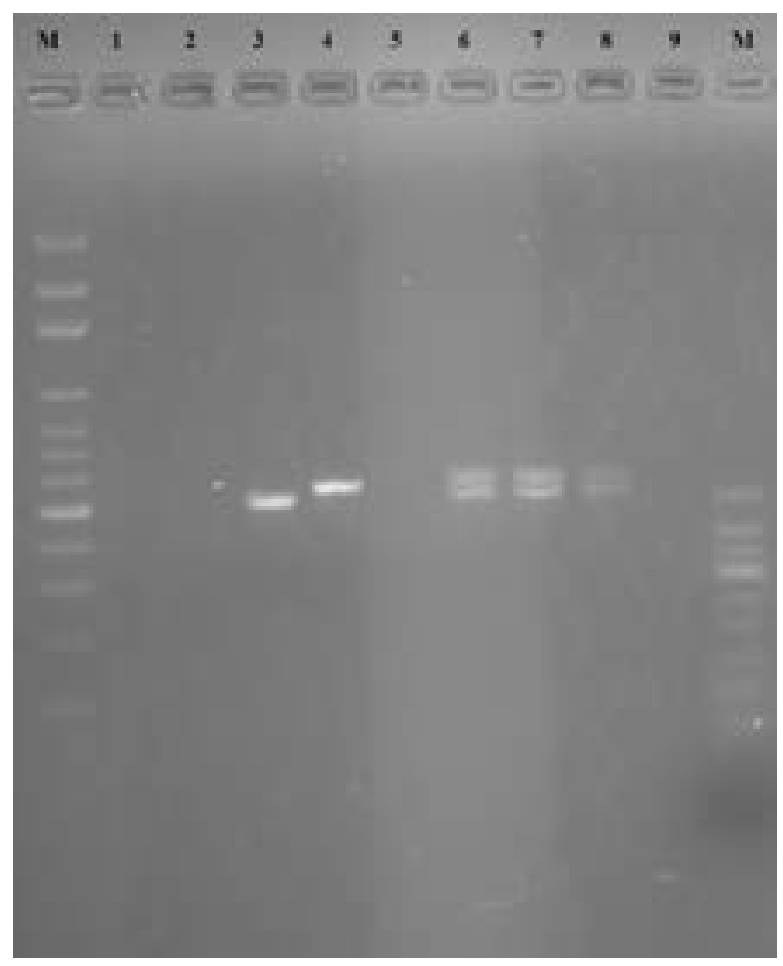

Figure 3. Gel image of the cpb gene region PCR. M. 100 bp Marker

1. Reference L. tropica (MHOM/AZ/1974/SAF-K27)

2. Reference L. major (MHOM/SU/1973/5ASKH)

3. Reference L. infantum (MHOM/TN/1980/IPT1)

4. Reference L. donovani (MHOM/IN/1980/DD8)

5. Reference L. aethopica (MHOM/ET/1972/L100)

6. Sample $1 \mathrm{~L}$. infantum/donovani hybrid (human)

7. Sample 2 L. infantum/donovani hybrid (dog)

8. Sample 3 L. infantum/donovani hybrid (phelobotomus)

9. Negative Control

10. 50 bp Marker" the bone marrow and lymph node aspirates while promastigotes were present in the EM. For patient serum, IFAT IgG was 1/256 positive, and rK39 was positive for both dog and human samples.

Of 52 Phlebotomus (24 male and 28 female), 35 were P.similis (12 male, 23 female), ten were $P$.neglectus/ syriacus (nine male, one female), six were P.papatasi (three male, three female) and one was P. tobbi (female) (Table 1). Molecular analysis showed an identical Leishmania strain in both the patient, dog, and P.tobbi. Melting curve analysis for the Real-time PCR revealed two peaks in all three samples and gel electrophoresis revealed two bands both compatible with $\mathrm{L}$. infantum and L. donovani regions in all three samples, thus leading to the conclusion that the infecting strain was a hybrid of L. infantum and L. donovani (Figure 3).

\section{Treatment}

After assessing the patient's severe clinical situation besides the unpredictable treatment response of the hybrid strain against pentavalent antimonials because of the reported antimonial resistance in the region (20), Liposomal amphotericin B was chosen as the drug of choice. Evaluating the patient as young and without any serious organic functional disorder and considering the high cure rates by liposomal amphotericin B therapy (21) he was administered liposomal amphotericin B with the dosage of $3 \mathrm{mg} / \mathrm{kg} /$ day for ten days with the total dose of $30 \mathrm{mg} / \mathrm{kg}$.

After the liposomal amphotericin B therapy, the patient's fever resolved, clinical symptoms regressed, and the blood tests returned to normal. He was externalized and was screened every 15 days for three months in the clinic. During these 3 months, his appetite was going better, and he started gaining weight, his liver and spleen returned to normal size, and his fever resolved. Because of the patient's refusal of a control bone marrow sampling, his peripheric blood smear was controlled for Leishmania spp. amastigotes and was evaluated negatively.

As for the CanL case, the dog was evaluated by a veterinarian and assessed as severe canine leishmaniasis (CanL). The dog was subjected to euthanasia by its owner, considering the clinical severity 
of its situation and the environment suitable for the infection chain with abundant vector sand flies in the surroundings,. It was recommended that the garden should be sprayed with insecticides.

\section{DISCUSSION}

The detection of the hybrid strain can be attributed to the developing molecular methods which enable us to differentiate Leishmania spp. through genomic and proteomic approaches. There is no possible way to show when or where the hybridization occurred with the present data, but there is good reason to suggest recent development of the L. infantum/donovani hybrid for various reasons. Firstly the hybrid strain was found in the Manisa region, which is in the western part of Turkey. Manisa is in the Mediterranean climatic zone and bears the rainfall characteristics of the Mediterranean climate. The rains are concentrated in winter while summers are dry. The warmest months are June, July, and August with temperatures rising above 30 ${ }^{\circ} \mathrm{C}$, the average temperature in July is $34.4{ }^{\circ} \mathrm{C}$ and the average temperature all around the year is 16.8 ${ }^{\circ} \mathrm{C}$. The minimum temperatures in winter do not go below $6{ }^{\circ} \mathrm{C}$. It is identified that Manisa has 162 summer days and an average of 107.5 days in a year the temperature is above $30^{\circ} \mathrm{C}$. The city is situated on the foot of Spil mountain, and a big part of the Gediz river flows through Manisa, very close to the ancient Lydian Empire's capital city Sardis (22).

Manisa city is an industrial and agricultural centre in the region, housing a population of 1380366 people in 2015 (23). It is also a neighbour city of Izmir, the 3rd most populous city in Turkey. Because of its location and job opportunities, Manisa attracts lots of immigration from all around Turkey (24). With the ongoing refugee crisis in the region, there are also lots of Syrian refugees immigrating to Manisa (25). Around 4 million registered Syrian refugees are now residing in Turkey. In Syria, 46398 new CL cases were reported in 2009 and 42165 in 2010, VL cases are sporadic $(26,27)$. The Syrian CL patients are also crossing the border to Turkey and settling in the cities. These patients' conditions are monitored by the Turkish Ministry of Health and documented. It is suspected that a large proportion of the refugees are CL patients and can easily carry the disease to Turkey (28).
With the rising population in the region and immigration from Leishmaniasis endemic regions, Leishmaniasis cases are increasing. This increase in the number of human and animal infections in the region coupled with the infections caused by different strains carried in by the human population movements may have generated a suitable environment for hybrid formation (29).

Interspecific hybrid formation among trypanosomatids has long been debated (30), but the mechanisms of hybridization have not been fully elucidated. Only recently, intraspecific hybridization has been demonstrated (7). Furthermore, the genetic diversity and structure of L. infantum populations and ways to discriminate them is under debate (31). Hybridization among different strains of Leishmania spp. may stand as a powerful tool for Leishmania genomic exchange and thus strain differentiation. In this study, we show a hybrid strain of L. donovani/L. infantum acquired from the sand fly P. tobbi midgut as well as the human and dog samples. These data strongly suggest that the L. infantum/ donovani hybrid strain is zoonotic and causes VL in humans and CanL in dogs. As to where the hybrid formation occurred remains unanswered, the previous studies suggest the permissive vector $P$. tobbi may play a role in hybrid formation $(8,32)$.

A study also shows a VL causing hybrid strain obtained from the Kuşadası region, which is also in western Turkey in the year 2001 (33). In that study, the hybrid strain was characterized by Multilocus Microsatellite Typing (MLMT) analysis, which is mostly used for population genetic studies. Also, in the same study, the hybridizing populations of Leishmania spp. were attributed to L. infantum MON1 , which is the prevalent zymodeme causing VL in Turkey and a non-MON-1 Turkish-Cypriotic population (33). No other study was published referring to a hybrid strain of Leishmania spp. from the region. Applying advanced population genetics and sequencing methods to those two hybrid strains may provide insights into the hybridization process. The only proven vector for L. infantum/donovani hybrid strain is P. tobbi.

Another issue that is open to debate is that this strain may not be a hybrid or a variant but an origi- 
nal species in itself. Recent literature shows increasing numbers L. infantum and L. donovani infections, and some of these cases are CL causing strains that are detected in Turkey (34). Further investigations of the exact molecular make-up of the genome of this L. infantum /donovani hybrid strain, as well as its pathological properties, needs to be carried out.

\section{CONCLUSIONS}

According to our findings, it is assumed that L. infantum and L. donovani strains have formed a hybrid strain and the resulting hybrid strain is capable of causing severe VL in humans and CanL in dogs, and the natural vector of this strain is P. tobbi. These findings are attributed to the mass population movements from Leishmania spp. endemic countries into our country. It is also assumed that hybrid Leishmania strains can pose a threat as emerging infectious agents for the region and our country and may also present itself with different clinical propagations and affect much larger populations.
Ethical Approval: Manisa Celal Bayar University Health Ethical Committee for Research Studies approved the study with the decision number of 20478486-307.

Peer-review: Externally peer-reviewed

Author Contributions: Concept - A.Ö., S.A., Ö.T., C.G.; Design - A.Ö., S.A., C.G.; Supervision - A.Ö., C.G., Ö.T.; Materials - A.Ö., S.A., I.Ç., A.Y.; Data Collection and/or Processing - A.Ö., İ.Ç., V.T., A.Y.; Analysis and/or Interpretation - V.T., İ.Ç., A.Y., C.G.; Literature Review -A.Ö., V.T., I.Ç.; Writer - V.T., A.Ö., İ.Ç.; Critical Reviews - A.Ö., S.A., Ö.T., C.G.

Conflict of Interest: The authors have no conflict of interest to declare.
Financial Disclosure: This study was supported by Scientific Research Projects Office of Manisa Celal Bayar University, Turkey, with several projects (Project Numbers: 2010-057 and 2014- 010).

Statement: This study was presented as a poster in the WorldLeish 6 (6th World Congress on Leishmaniasis) between 16-20 May 2017 in Toledo, Spain.

Acknowledgements: The authors would like to address special thanks to Dr. Aldert Bart and Dr. Tom van Gool from Amsterdam University and Parasite Bank of Manisa Celal Bayar University Faculty of Medicine, Turkey.

\section{REFERENCES}

1 World Health Organization. Control of the leishmaniases. World Health Organ Tech Rep Ser 2010; xii-xiii, 1-186.

2 Alemayehu B, Alemayehu M. Leishmaniasis: a review on parasite, vector and reservoir Host. Health Sci J 2017; 11. doi: 10.21767/1791-809x.1000519

3 World Health Organization. Leishmaniasis. WHO 2017 (cited 2017 January 9). Available from: URL: http://www.who.int/ leishmaniasis/en/

4 Gürel MS, Yeşilova Y, Olgen MK, Ozbel Y. Türkiye'de kutanöz leishmaniasisin durumu (Cutaneous leishmaniasis in Turkey) Turkiye Parazitol Derg 2012; 36: 121-9.

5 Ozbel Y. The infections transmitted by Sand flies in Turkey. Ankara Univ Vet Fak Derg 2013; 60: 225-8.

6 Ready PD. Leishmaniasis emergence in Europe. Euro Surveill 2010; 15: 19505

7 Gibson W, Peacock L, Ferris V, Fischer K, Livingstone J, Thomas J, et al. Genetic recombination between human and animal parasites creates novel strains of human pathogen. PLoS Negl Trop Dis 2015; 9: e0003665.
8 Akopyants NS, Kimblin N, Secundino N, Patrick R, Peters N, Lawyer $\mathrm{P}$, et al. Demonstration of genetic exchange during cyclical development of Leishmania in the sand fly vector. 2009; 324: 265-8.

9 Inbar E, Akopyants NS, Charmoy M, Romano A, Lawyer P, Elnaiem DE, et al. The mating competence of geographically diverse Leishmania major strains in their natural and unnatural sand fly vectors. PLoS Genet 2013; 9: e1003672.

10 Rogers MB, Downing T, Smith BA, Imamura H, Sanders M, Svobodova $\mathrm{M}$, et al. Genomic confirmation of hybridisation and recent inbreeding in a vector-isolated Leishmania population. PLoS Genet. 2014;10: e1004092.

11 Miles MA, Yeo M, Mauricio IL. Genetics. Leishmania exploit sex. Science 2009; 324: 187-9.

12 Miles MA, Llewellyn MS, Lewis MD, Yeo M, Baleela R, Fitzpatrick S, et al. The molecular epidemiology and phylogeography of Trypanosoma cruzi and parallel research on Leishmania: looking back and to the future. Parasitology 2009; 136: 1509-28.

13 Kato H, Cáceres AG, Hashiguchi Y. First Evidence of a hybrid of Leishmania (Viannia) braziliensis/L. (V.) peruviana DNA de- 
tected from the Phlebotomine sand fly Lutzomyia tejadai in Peru. PLoS Negl Trop Dis 2016; 10: e0004336.

14 Nolder D, Roncal N, Davies CR, Llanos-Cuentas A, Miles MA Multiple hybrid genotypes of Leishmania (viannia) in a focus of mucocutaneous leishmaniasis. Am J Trop Med Hyg 2007; 76: $573-8$.

15 Ozensoy Toz S, Ertabaklar H, Gocmen B, Demir S, Karakus M, Arserim SK, et al. Kuzey Kibris'ta kanin leishmaniasis ve kum sineklerinin epidemiyolojisi. Turkiye Parazitol Derg 2013; 37: 107-12.

16 Özbilgin A, Çulha G, Uzun S, Harman M, Topal SG, Okudan F, et al. Leishmaniasis in Turkey: First clinical isolation of Leish mania major from 18 autochthonous cases of cutaneous leishmaniasis in four geographical regions. Trop Med Int Heal 2016; 21: 783-91.

17 Iovannisci DM, Ullman B. Single cell cloning of Leishmania parasites in purine-defined medium: isolation of drug-resistant variants. Adv Exp Med Biol 1984; 165: 239-43.

18 Toz SO, Culha G, Zeyrek FY, Ertabaklar H, Alkan MZ, Vardarli AT, et al. A Real-Time ITS1-PCR based method in the diagnosis and species identification of Leishmania parasite from human and dog clinical samples in Turkey. PLoS Negl Trop Dis 2013; 7: e2205

19 Hide M, Bañuls AL. Species-specific PCR assay for L. infantum/L. donovani discrimination. Acta Trop 2006; 100: 241-5.

20 Cascio A, Colomba C. La leishmaniosi viscerale in età pediatrica (Childhood Mediterranean visceral leishmaniasis). Infez Med 2003; 11: 5-10.

21 Rosenthal E, Delaunay P, Jeandel PY, Haas H, Pomares-Estran C, Marty P. Le traitement de la leishmaniose viscérale en Europe en 2009. Place de l'amphotéricine B liposomale (Liposomal amphotericin B as treatment for visceral leishmaniasis in Europe, 2009). Med Mal Infect. 2009; 39: 741-4.

22 Turkish Ministry of Culture and Tourism. Manisa geoghraphical and climatic properties (cited 2016 February 9). Available from: URL: https://manisa.ktb.gov.tr/TR-151846/cografi-yapi. html

23 Population of Manisa city. (cited 2015). Available from: URL: https://biruni.tuik.gov.tr/medas/

24 Duruiz D. Seasonal agricultural workers in Manisa: Materialization of labor, bodies and places through everyday encounters. Boğaziçi University, master thesis, 2011.
25 Aras NG, Mencutek Z. The international migration and foreign policy nexus: the case of Syrian refugee crisis and Turkey. Migrat 2015; 12: 193-208.

26 Rehman K, Walochnik J, Mischlinger J, Alassil B, Allan R, Ramharter M. Leishmaniasis in northern Syria during civil war. Emerg Infect Dis 2018; 24: 1973-81.

27 Alvar J, Vélez ID, Bern C, Herrero M, Desjeux P, Cano J, et al. Leishmaniasis worldwide and global estimates of its incidence. PLoS One 2012; 7: e35671.

28 Salman IS, Vural A, Unver A, Saçar S. Suriye iç savaşı sonrası Nizip'te kutanöz leyşmanyazis olgulan (Cutaneous leishmaniasis cases in Nizip, Turkey after the Syrian civil war) Mikrobiyol Bul. 2014; 48: 106-13.

29 Özbilgin A, Gencoglan G, Tunali V, Çavuş İ, Yıldırım A, Gündüz C, et al. Refugees at the crossroads of continents: a molecular approach for cutaneous leishmaniasis among refugees in Turkey. Acta Parasitol 2020; 65: 136-43.

30 Jenni L, Marti S, Schweizer J, Betschart B, Le Page RW, Wells JM, et al. Hybrid formation between African trypanosomes during cyclical transmission. Nature 1986; 322: 173-5.

31 Gouzelou E, Haralambous C, Antoniou M, Christodoulou V, Martinković F, Zivičnjak T, et al. Genetic diversity and structure in Leishmania infantum populations from southeastern Europe revealed by microsatellite analysis. Parasit Vectors 2013; 6: 342 .

32 Seblova V, Myskova J, Hlavacova J, Votypka J, Antoniou M, Volf P. Natural hybrid of Leishmania infantum/L. donovani: development in Phlebotomus tobbi, P. perniciosus and Lutzomyia longipalpis and comparison with non-hybrid strains differing in tissue tropism. Parasit Vectors 2015; 8: 605.

33 Gouzelou E, Haralambous C, Amro A, Mentis A, Pratlong F, Dedet JP, et al. Multilocus microsatellite typing (MLMT) of strains from Turkey and cyprus reveals a novel monophyletic L. donovani Sensu Lato group. PLoS Negl Trop Dis 2012; 6: e1507.

34 Özbilgin A, Töz S, Harman M, Topal SG, Uzun S, Okudan F, et al. The current clinical and geographical situation of cutaneous leishmaniasis based on species identification in Turkey. Acta Trop 2019; 190: 59-67. 